\title{
ANALISIS PENGARUH DAMPAK TATA RUNG KOTA DAN ANTUSIAS MASYARAKAT DALAM MENGGUNAKAN MASS RAPID TRANSIT (MRT) TERHADAP PENGURANGAN KEMACETAN DKI JAKARTA (LEBAK BULUS-HOTEL INDONESIA)
}

\author{
Ana Ramadhayanti \\ Universitas Bina Sarana Informatika \\ J1. Kamal Raya No.18, Ringroad Barat, Cengkareng - Jakarta Barat \\ Email: ana.rdx@bsi.ac.id
}

\begin{abstract}
Abstrak: Berbagai usaha mulai dilakukanoleh pemerintah untuk mengatasi kemacetan mulai darikemunculan moda transportasi smart city seperti busway dan OK TRIP yang saat ini telah hadir dimasyarakat. Sebagai perkembangan dari hal tersebut kini pemerintah telah menghadirkan MRT dengan rute Budaran Hotel Indonesia-Lebak Bulus Grab. Namun hadirnya MRT tersebut harus didukung dengan antusias masyarakat untuk menggunakan MRT.Salah satu wujud dukungan antusias tersebut salah satunya yakni meninggalkan kendaraan pribadi lalu beraralih kekendaraan umum atau transportasi umum. Dengan adanya pembangunan MRT telah merubah tata ruang kota, seperti telah dibuatnya jembatan layang dan lainlain. Untuk mengetahui lebih lanjut Dampak Tata Rung Kota dan Antusias Masyarakat Dalam Menggunakan Mass Rapid Transit (MRT) Terhadap Pengurangan Kemacetan DKI Jakarta maka harus dilakukan penelitian lebih lanjut. Penelitian ini menggunakan penelitian Kuantitatif, dengan jenis data primer yakni dengan membagikan kuesioner kepada pengguna MRT Jakarta rute Bundaran Hotel Indonesia-Lebak Bulus Grab. Hasil penelitian menujukkan bahwa menjukkan hasil Dampak Tata Rung Kota (X1) dan Antusias Masyarakat (X2) secara bersama-sama mempunyai pengaruh yang signifikan terhadap Pengurangan Kemacetan DKI Jakarta (Y). Semoga dengan dilakukan penelitian ini masyarakat berpartisipasi mendukung program pemerintah dalam mengurangi kemacetan.
\end{abstract}

Kata kunci: MRT; Hotel Indonesia; tata rung kota.

\begin{abstract}
Various attempts have been made by the government to overcome congestion starting from the emergence of smart city transportation modes such as busway and OK TRIP which are now present in the community. As a development of this, the government has now presented the MRT with the Budaran Hotel Indonesia-Lebak Bulus Grab route. But the presence of the MRT must be supported with enthusiasm from the public to use the MRT. One of the forms of enthusiastic support is one of which is leaving a private vehicle and shifting from public transportation or public transportation. With the construction of the MRT has changed the spatial structure of the city, such as the construction of an overpass and others. To find out more about the Impact of Urban Spatial Planning and Community Enthusiasm in Using Mass Rapid Transit (MRT) on Reduction of DKI Jakarta Congestion, further research should be carried out. This research uses quantitative research, with the type of primary data that is by distributing questionnaires to users of the Jakarta MRT roundabout route Hotel Indonesia-Lebak Bulus Grab. The results showed that the results of the Impact of City Spatial Planning (X1) and Community Enthusiasm (X2) together had a significant influence on the Reduction of Congestion in DKI Jakarta (Y). Hopefully with this research the community will participate in supporting government programs to reduce congestion.
\end{abstract}

Keywords: MRT; Hotel Indonesia; city pla.

\section{PENDAHULUAN}

Macet di ibu kota bukanlah suatu hal yang baru, problematika kemacetan di ibukota DKI Jakarta sudah menjadi hal yang telah lama terjadi. Berbagai hal telah diupayakan oleh pemerintah mulai dari hadirnya Transjakarta (transportasi Bus Rapid Transit), OK-OTrip yang saat ini berubah nama menjadi Jak Lingko, serta yang saat ini baru diluncurkan yakni Moda Raya Terpadu (MRT) Jakarta. Kehadiran MRT dengan rute Hotel Indonesia-Lebak Bulus merupakan cara untuk mengurangi kemacetan. Meski telah lama diuji coba sejak Maret 2019, namun antusias masyarakat meng- gunakan MRT cukup besar. Rute yang dilewati oleh MRT yakni Bundaran HI- Duku Atas BNI-Setibudi Astra-Bendungan Hilir-Istora Mandiri- SenayanASEAN- Blok M BCA- Blok A-Haji Nawi-Cipete Raya-Fatmawati-Lebak Bulus Grab. Selain harga yang cukup murah, kecepatan MRT juga terbilang cukup cepat, sehingga tidak heran jika masyarakat lebih memilih angkutan MRT sebagai alternative untuk menghindari kemacetan. Berbeda dengan kereta api yang beroperasi di bawah, MRT merupakan moda transportasi yang beroperasi di atas jalan laying atau jembatan sehingga tidak heran jika dengan hadirnya MRT merubah tata ruang kota, terutama dari sisi bangunan. Jembatan MRT terbilang 
cukup tinggi seperti salah satunya terlihat dari gambar dibawah ini yang memperihatkan ketinggian dari jembatan MRT. Dikutip dari bbc.com William Sabandar Direktur Utama MRT Jakarta, mengatakan mendorong warga Jakarta beralih dari kendaraan pribadi ke transportasi publik, terutama MRT, adalah pekerjaan rumit. Apalagi, kata dia, selama ini baru $20 \%$ penduduk Jakarta yang rutin menumpang angkutan umum setiap hari. Menurut (Muslim, 2018) dalam penelitiannya menjelaskan Kemajuan Singapura dalam sistem transportasinya dapat mengatasi kemacetan dengan menggunakan MRT (Mass Rapid Transit). MRT ini dihubungkan dengan jalur-jalur penting seperti pusat perbelanjaan, sekolah, kantor maupun ketempat hiburan. Untuk pengguna jalan kaki juga mendapat perhatian dari pemerintah dengan dibuatkan jalur pejalan kaki dan penyandang disabilitas agar dapat menikmati perjalanannya. Untuk mengetahui Dampak Tata Rung Kota dan Antusias Masyarakat Dalam Menggunakan Mass Rapid Transit (MRT) Terhadap Pengurangan Kemacetan DKI Jakarta maka peneliti melakukan penelitian lebih lanjut
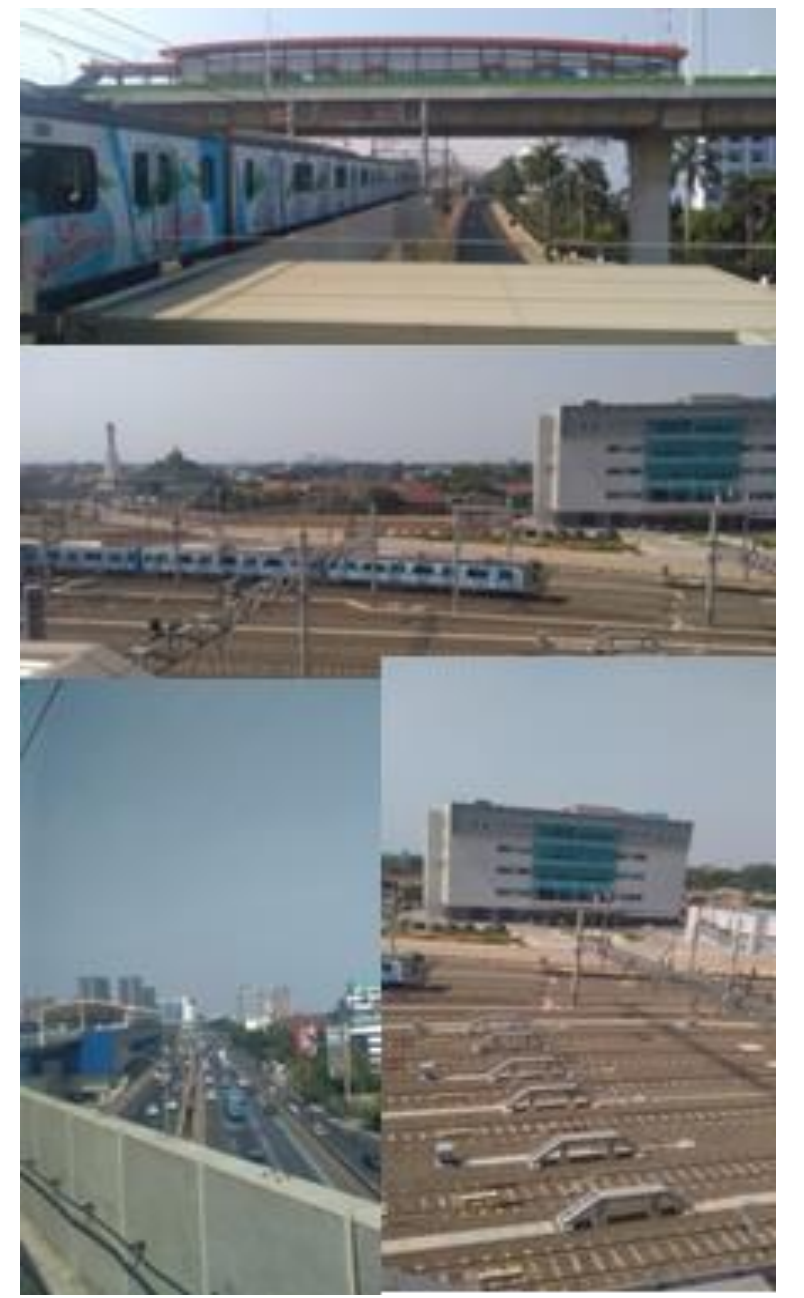

Gambar 1. Tata Ruang Kota MRT Jakarta

\section{TINJAUAN PUSTAKA}

\section{Tata Ruang Kawasan Perkotaan}

Menurut (Yunus, 2014) Adapun kegiatan yang merupakan "ciri kawasan perkotaan " meliputi tempat permungkiman, perkotaan serta tempat pemusatan dan pendistribusian kegiatan bukan pertanian, seperti pelayanan jasa pemerintahan, sosial, dan ekonomi (Penjelasan Pasal 5 ayat (4) UUPR).

Rencana Tata Runag Wilayah Kota (RTRW Kota), sebagaimana diatur dalam Pasal 28-Pasal 31 UUPR, pada dasarnya sama dengan penyusunan RTRWK, yakni berlaku kententuan Psala 25, Pasal 26, dan Pasal 27 uu UUPR, "dengan ketentuan ditambahkan :a) Rencana Penyediaan dan Pemanfaatan Jalur Hijau; c) Rencana Penyediaan dan Pemanfaatan Ruang Terbuka Nonhijau; dan c) Rencana Penyediaan dan Pemanfaatan Prasana dan Srana Pejalan Kkai, Angkutan Umum, Kegiatan sektor informal, dan ruang evakuasi bencana, yang dibutuhkan untuk menjalankan fungsi wilayah kota sebagai pusat pealayanan sosial ekonomi dan pusat pertumbuhan wilayah" (Pasal 28 UUPR).

Menurut (Rustiadi, 2017) Pengembangan transportasi darat yang juga penting adalah pengembangan jalur kereta api, yang dapat memberikan efisiensi transportasi antar wilayah secara masif.

\section{Antusias}

Menurut (Sina, n.d.) Antusias adalah suatu semangat yang membuat kita untuk segera bertindak melakukan sesuatu. Suatu semangat yang sangat dahsyat untuk segera bertindak dan tidak mau menundanunda lagi. Untuk itu bagaimana kita memicu antusias merupakan pertanyaan krusial untuk dipikirkan. Salah satu cara untuk memicu antusias yaitu melalui kesadaran akan arti hidup ini.

\section{MRT}

Menurut (Susantono, 2014) MRT secara harafiah dapat diartikan sebagai moda angkutan yang mampu mengangkut penumpang dalam jumlah yang banyak (massal) dengan frekuensi dan kecepatan yang sangat tinggi (rapid).

Biasanya MRT merupakan bagian dari implementtasi system transportasi umum terpadu, yaitu sitem transportasi yang mmapu menghubungkan orang atau barang dari satu titik ke titik lain secara efisien, serta memiliki kemudahan dalam melakukan perpindahan dari satu moda ke moda lain tanpa mengurangi waktu tempuh perjalanan. 
Pengembangan dari system yang terpadu akan menjadikan MRT tidak hanya berfungsi sebagai sarana angkutan yang efisien, tetapi juga instrument yang nadal untuk mengarahkan perkembangan sebuah kota besar.

Menurut (Sihmanto, 2010) Light Rail Transit (LRT) dan Metro Rail Transit (MRT) sebenarnya sama, hanya rutenya yang berbeda. Transportasi massal ini merupakan andalan utama Pemerintah Kota Metro Manila untuk menghindari kemacetan lalu lintas Kota Manila pada jam sibuk kerja.

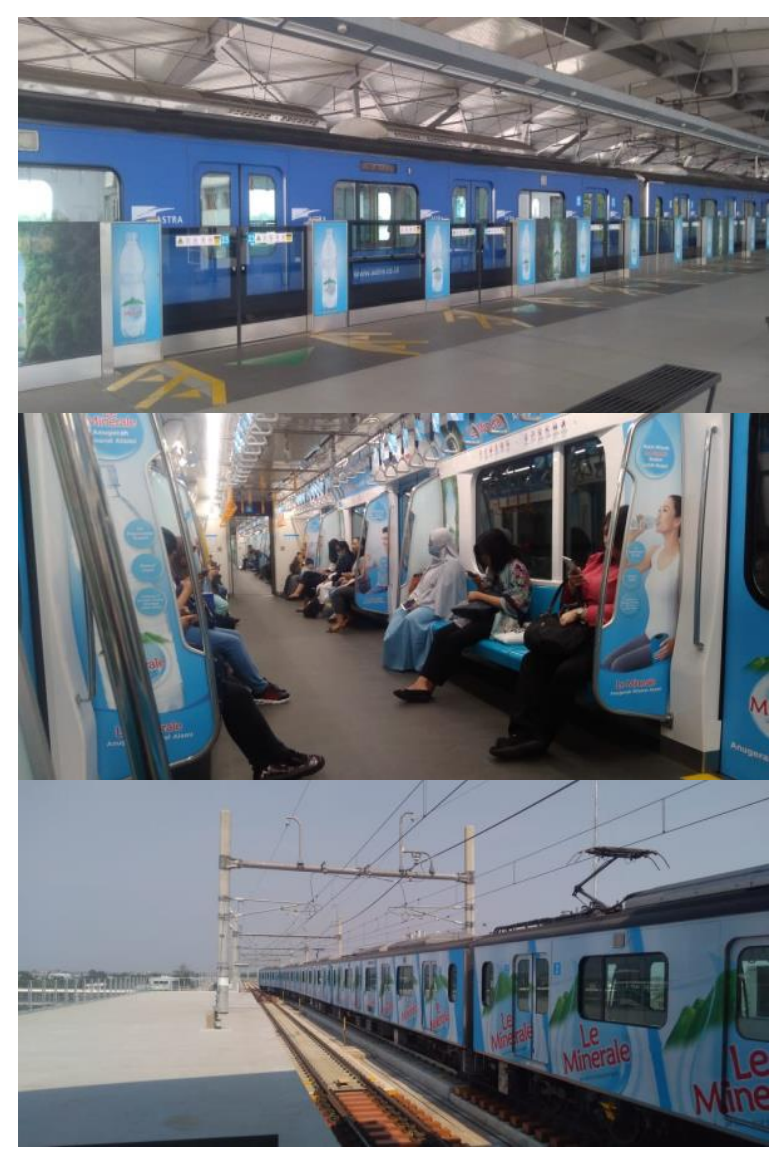

Gambar 2. Foto MRT Jakarta

\section{MRT dan Kelebihannya}

Menurut (Susantono, 2014) Berdasarkan posisi lintasannya, MRT dapat dibagi menjadi tiga jenis yaitu:

- Surface (di permukaan tanah)

- Elevated (melayang), dan

- Subway (dibawah tanah)

Yang pertma, SurfaceMRT alias MRT yang mengular di permungkaan tanah. Tipe ini mirip kereta dengan jalur lintasan khusus, dan secara ekonomi dianggap paling murah biayannya ketimbang dua jenis lainnya.
Apalagi MRT yang punya kecepatan tinggi tidak cocok dibangun di permukaan tanah Jakarta yang sudah cukup kisruh dengan pengguna jalan yang terkadang melanggar jalurnya. SElian tidak akan efektif, kita perlu pertimbangkan hambatan di perlintasan sebidang.

Yang kedua: Elevated MRT. Berbeda dengan MRT jenis Surface, tiap kedua ini lintasannya dibangun di atas tiang-tinag yang berdidi pada median jalan sehingga tidak mengganggu lalau lintas darat yang sudh ada. Pembangunan MRT dengan lintasan Eleveted ini mempertimbangkan beberapa faktor, seperti tidak adanya lahan yang tersedia untuk membangun jalur MRT serta banyaknya perlintasan sebidang pada jalur lintasan MRT.

Alternatif ketiga, Subway MRT. Tipe terakhir ini lintasannya berada di bawah tanah dengan cara mellaui terowongan sebagai jalur khususnya. Subway $M R T$ biasanya dibangun di pusat kota yang padat untuk menghindari banyaknya perlintasan sebidang serta menjaga estetika lanskap perkotaan agar terlihat rapi dan indah.

\section{Sarana dan Prasarana Angkutan}

Menurut (Sri \& Pamungkas, 2014) Seperti disebutkan di atas, jaringan jalan raya di dalam kota harus ditambah untuk menghindari kemacetan yang sudah amat serius; penambahan jaringan jalan itu sering dengan pembenahan tata-kota secara nasional. Jalan-jalan tol dengan tool-fee sebaiknya ditutup, diganti dengan jalan bebas hambatan. Adanya toolroad itu sama saja membisniskan fasilitas umum yang wajib disediakan oleh setiap pemerintah dengan gratis, bukan si Pemakai jalan yang justru menjadi korbannya.

Banyak cara untuk meghindari kemaceten, antara lain, perlu dibangunnya public transportation sebanyak mungkin; apalagi yang bisa bergerak cepat dan masal, seperti MRT, Ma-Rapid Trnasport. Dengan public transportation itu bisa dihindarkan pemakaian kendaraan-kendaraan pribadi. Disekitar tiap halte angkutan umum itu perlu dibangun pula tempat-tempat parkir umum agar pengendara mobil pribadi bisa pindah memakai angkutan umum. Selain itu, harus pula dibangun jalan-jalan laying sebanyak mungkin untuk menghindrai persimpangan Cara-cara round-about dengan menciptkan jalan searah adalah yang paling mudah dilakukan.

Dengan berbagai upaya menghindari kemacetan di dalam kota itu, konsumsi BBM pun bisa dikurangi, sehingga biaya untuk subsidi BBM pun bisa berkurang. 


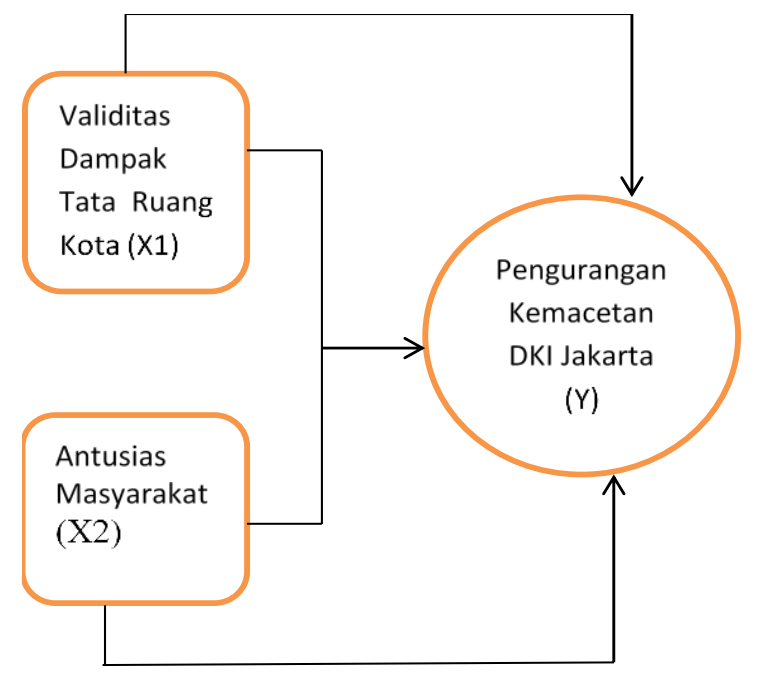

Gambar 3. Kerangka Pemikiran

\section{Hipotesis}

(Timotius, 2017) Hipotesis adalah dugaan atau jawaban sementara atas permasalahan penelitian. Untuk itu, diperlukan data atau fakta untuk membuktikan kebenaran suatu hipotesis. Hipotesis di buat berdsarkan pemikiran teoritis atau dari penelitian pendahuluan. Hipotesis yang baik harus jelas dan spesifik serta dapat diuji.

\section{METODE PENELITIAN}

Penelitian ini menggunakan jenis penelitian kuntitatif, dengan membagikan kuesioner kepada pengguna MRT Jakarta.

\section{Populasi}

Populasi penelitian ini adalah pengguna MRT Jakarta. Dikutip dalam kompas.com diketahui pengguna MRT dalam sehari berkisar sebanyak 70.000.

\section{Sampel}

Pengambilan sampel menggunakan rumus Slovin yakni.

dimana:

$$
\mathrm{n}=\frac{N}{1+N e^{2}}
$$

$\mathrm{n}=$ jumlah sampel

$\mathrm{N}=$ jumlah populasi

$\mathrm{e}=$ batas toleransi kesalahan (error tolerance)

$\mathrm{n}=\frac{70000}{1+70000 \times .0 .05^{2}}=\frac{70000}{1+70000 \times 0,0025}=\frac{70000}{1+175}$

$=\frac{70000}{176}$

=397,727 dibulatkan (398)

Dari jumlah populasi 70.000 setelah dilakukan perhitungan dengan menggunakan rumus slovin maka didapatkan sampel berjumlah 398 .

\section{Variabel Penelitian}

(Timotius, 2017) Varibel adalah elemen atau karakter yang dipelajari. Parameter adalah elemen yang tidak berubah, misalnya usia, angka dari subjek tertentu. Variabel (parameter) penelitian adalah suatu atau kumpulan ciri dari objek yang diteliti.

Variabel bebas adalah variabel yang mempengaruhi variabel lain.

Varibel terikat adalah variabel yang dipengaruhi oleh variabel lain (dalam hal ini variabel bebas).

Menurut (Fatuhudin, 2015) Penelitian Kuantitatif adalah penelitian yang menggunakan pendekatan yang bersifat obyektif, mencakup pengumpulan dan analisis data kuantittaif serta menggunakan metode pengujian statistik.

\section{ANALISA DAN PEMBAHASAN}

\section{Uji Validitas}

(Umar, 2003) Seperrti telah diterangkan di bagian terdahulu, validitas menujukkan sejauh mana suatu alat pengukur dapat mengukur apa yang ingin diukur. Jika periset menggunakan kuesioner dalam pengumpulan data, kuesioner yang disusunnya harus mengukur apa yang ingin diukurnya. Setelah kuesioner tersebut tersusun dan teruji validitasnya, dalam praktek belum tentu data yang terkumpul adalah data yang valid.

Tabel 1. Uji Validitas Dampak Tata Rung Kota (X1)

\begin{tabular}{cccc}
\hline Butir Item $(\mathbf{X 1 )}$ & R tabel & R hitung & Keterangan \\
\hline Item 1 & 0,095 & 0,845 & Valid \\
Item 2 & 0,095 & 0,782 & Valid \\
Item 3 & 0,095 & 0,840 & Valid \\
Item 4 & 0,095 & 0,570 & Valid \\
Item 5 & 0,095 & 0,840 & Valid \\
Item 6 & 0,095 & 0,892 & Valid \\
Item 7 & 0,095 & 0,733 & Valid \\
Item 8 & 0,095 & 0.822 & Valid \\
\hline
\end{tabular}

Sumber: Hasil Olah Data SPSS24

Tabel 2. Uji Validitas Antusias Masyarakat (X2)

\begin{tabular}{cccc}
\hline Butir Item $(\mathbf{X 2})$ & R tabel & R hitung & Keterangan \\
\hline Item 1 & 0,095 & 0,854 & Valid \\
Item 2 & 0,095 & 0,798 & Valid \\
Item 3 & 0,095 & 0,848 & Valid \\
Item 4 & 0,095 & 0,533 & Valid \\
Item 5 & 0,095 & 0,837 & Valid \\
Item 6 & 0,095 & 0,888 & Valid \\
Item 7 & 0,095 & 0,764 & Valid \\
Item 8 & 0,095 & 0,869 & Valid \\
\hline
\end{tabular}

Sumber: Hasil Olah Data SPSS24 
Tabel. 3. Pengurangan Kemacetan DKI Jakarta (Y)

\begin{tabular}{cccc}
\hline Butir Item (Y) & R tabel & R hitung & Keterangan \\
\hline Item 1 & 0,095 & 0,823 & Valid \\
Item 2 & 0,095 & 0,798 & Valid \\
Item 3 & 0,095 & 0,785 & Valid \\
Item 4 & 0,095 & 0,603 & Valid \\
Item 5 & 0,095 & 0,765 & Valid \\
Item 6 & 0,095 & 0,850 & Valid \\
Item 7 & 0,095 & 0,712 & Valid \\
Item 8 & 0,095 & 0,764 & Valid \\
\hline
\end{tabular}

Sumber: Hasil Olah Data SPSS24

Menurut (Oktavia, 2015) Validitas merupakan ketepatan atau kecermatan pengukuran. Suatu kuesioner dikatakan valid kalau pertanyaan mampu mengungkapkan sesuatu yang akan diukur oleh kuesioner tersebut. Suatu variabel (pertanyaan) dikatakan valid bila skor variabel tersebut berkorelasi secara signifikan dengan skor totalnnya.

Keputusan Uji Validitas:

a) Bila $\mathrm{r}$ hitung ( $r$ person $)>\mathrm{r}$ tabel; artinya pertanyaan tersebut valid.

b) Bila $r$ hitung $(r$ pearson $)<\mathrm{r}$ tabel; artinya pertanyaan tersebut tidak valid.

Hasil olah data menggunakan SPSS 24. Untuk uji hasil uji Validitas X1, X2 dan Y dinyatakan valid karena hasil perhitungan $\mathrm{R}$ hitung lebih besar jika dibandingkan dengan nilai $\mathrm{R}$ tabel.

Sedangkan menurut Riwidikto dalam Oktavia (2015), cara paling mudah dalam membaca hasil uji adalah berdasarkan nilai signifikasi ( $\mathrm{p}$ ) yang besarnya 0,000 yang dibandingkan dengan nilai $\mathrm{a}=5 \%$, dimana nilai $\mathrm{p}<0,05)$ sehingga menujukkan bahwa pertanyaan tersebut valid karena memiliki hubungan yang signifikan antara pertanyaan dengan jumlah skor total pertanyaan.

Hasil perhitungan uji validitas untuk nilai X1, X2 dan Y menujukkan nilai Sig. $<0,05$.

\section{Uji Realibilitas}

(Sitinjak, 2004) Langkah selanjutnya adalah melakukan uji realibilitas dengan menngunakan alat uji Spearman-Brown. Uji realibilitas dilakukan dengan membandingkan antara $r$ hitung dan $r$ tabel. Proses uji realibilitas dapat dilihat dalam Lampiran.

Tabel 4. Uji Realibilitas Dampak Tata Rung Kota (X1)

\begin{tabular}{|c|c|c|c|}
\hline \multicolumn{4}{|c|}{ Case Processing Summary } \\
\hline & & & $\%$ \\
\hline \multirow[t]{3}{*}{ Cases } & Valid & 398 & 100,0 \\
\hline & Excluded $^{\mathrm{a}}$ & 0 & ,0 \\
\hline & Total & 398 & 100,0 \\
\hline
\end{tabular}

a. Listwise deletion based on all variables in the procedure.

Reliability Statistics

\begin{tabular}{|c|c|}
\hline Cronbach's Alpha & $\mathrm{N}$ of Items \\
\hline ,903 & 8 \\
\hline
\end{tabular}

Tabel 5. Uji Realibilitas Antusias Masyarakat (X2)

\begin{tabular}{llrr}
\multicolumn{3}{c}{ Case Processing Summary } \\
\hline \multicolumn{3}{c}{ N } & \multicolumn{1}{c}{$\%$} \\
\hline Cases & Valid & 398 & 100,0 \\
& Excluded $^{\mathrm{a}}$ & 0 &, 0 \\
& Total & 398 & 100,0 \\
\hline
\end{tabular}

a. Listwise deletion based on all variables in the procedure.

Reliability Statistics

\begin{tabular}{rr}
\hline Cronbach's Alpha & N of Items \\
\hline, 909 & 8 \\
\hline
\end{tabular}

Sumber: Hasil Olah Data SPSS24

Tabel 6. Uji Realibilitas Pengurangan Kemacetan DKI Jakarta (Y)

\begin{tabular}{|c|c|c|c|}
\hline \multicolumn{4}{|c|}{ Case Processing Summary } \\
\hline & & & $\%$ \\
\hline \multirow[t]{3}{*}{ Cases } & Valid & 398 & 100,0 \\
\hline & $\begin{array}{l}\text { Exclu } \\
\operatorname{ded}^{\mathrm{a}}\end{array}$ & 0 &, 0 \\
\hline & Total & 398 & 100,0 \\
\hline
\end{tabular}

a. Listwise deletion based on all variables in the procedure.

Reliability Statistics

\begin{tabular}{rr} 
Cronbach's Alpha & N of Items \\
\hline 909 & 8 \\
\hline
\end{tabular}

Sumber: Hasil Olah Data SPSS24

Menurut (Oktavia, 2015) Realibilitas artinya kestabilan pengukuran. Alat dikatakan reliabel jika digunakan berulang-ulang nilai sama. Sedangkan pertanyaan dikatakan reliabel, jika jawaban seseorang terhadap pertanyaan konsiten atau stabil dari waktu ke waktu. Keputusan Uji Realibilitas:

a) Bila nilai Crobanch's Alpha $>$ konstanta $(0,6)$, maka pertanyaan reliabel.

b) Bila nilai Crobanch's Alpha < konstanta $(0,6)$, maka pertanyaan tidak reliabel.

Hasil perhitungan uji realibilitas untuk ketiga variabel diatas $\mathrm{X} 1, \mathrm{X} 2$ dan $\mathrm{Y}$ menujukkan bahwa nilai X1 0,903> 0,6, X2 0,909>0,6 dan Y 0,909> 0,6 .

\section{Uji Regresi}

Angka R square adalah $0,715, \mathrm{R}$ square dapat disebut koefisien determinasi, yang dalam hal ini berarti $71,5 \%$ dari variasi Pengurangan Kemacetan DKI Jakarta (Y) dapat dijelaskan oleh varaiabel Dampak Tata Rung Kota (X1) dan Dampak Tata Rung Kota (X2). Sedangkan sisanya $(100 \%-71,5 \%=$ $28.5 \%$ ) dijelaskan oleh sebab-sebab yang lain. Menurut (Santoso, 2018) R square berkisar pada angka 0 sampai 1 , dengan catatn semakin kecil $R$ square, semkin lemah hubungan kedua variabel. 
Tabel 7. Uji Regresi

\begin{tabular}{|c|c|c|c|c|c|}
\hline \multicolumn{6}{|c|}{ Model Summary ${ }^{\mathbf{b}}$} \\
\hline Model & $\mathbf{R}$ & $\begin{array}{c}\text { R } \\
\text { Square }\end{array}$ & $\begin{array}{l}\text { Adjusted R } \\
\text { Square }\end{array}$ & $\begin{array}{c}\text { Std. Error } \\
\text { of the } \\
\text { Estimate }\end{array}$ & $\begin{array}{l}\text { Durbin- } \\
\text { Watson }\end{array}$ \\
\hline 1 & $846^{\mathrm{a}}$ & ,715 &, 714 & 2,096 & 1,844 \\
\hline $\begin{array}{l}\text { a. Predi } \\
\text { Rung } \\
\text { b. Depe } \\
\text { Sumber }\end{array}$ & $\begin{array}{l}\text { ors: (C } \\
\text { Kota } \\
\text { dent V } \\
\text { Hasil }\end{array}$ & $\begin{array}{l}\text { onstant), } \\
\text { (1) } \\
\text { ariable: } \mathrm{P} \\
\text { lah Data }\end{array}$ & $\begin{array}{l}\text { ngurangan Ke } \\
\text { SPSS } 24\end{array}$ & arakat $(\mathrm{X} 2), \mathrm{I}$ & ampak Tata \\
\hline
\end{tabular}

\section{Uji Signifikasi Pengaruh Parsial (Uji t)}

Uji t digunakan untuk menguji signifikasi hubungan variabel bebas $(\mathrm{X})$ dan variabel terikat $(\mathrm{Y})$, apakah variabel bebas $(\mathrm{X})$ benar-benar berpengaruh terhadap variabel terikat $(\mathrm{Y})$ secara terpisah atau parsial. adalah:

Hipotesis yang diajukan dalam pengujian ini

H0: Variabel bebas (X) tidak mempunyai pengaruh yang signifikan terhadap variabel terikat $(\mathrm{Y})$ secara terpisah.

Ha: Variabel bebas $(\mathrm{X})$ mempunyai pengaruh yang signifikan terhadap variabel terikat $(\mathrm{Y})$ secara terpisah

Kriteria pengujian hipotesisnya adalah sebagai berikut:Menurut Muhid dalam (Fauzi, 2017) dengan cara membandingkan nilai t-hitung dengan nilai ttabel

Jika nilai t-hitung > nilai t-tabel maka H0 ditolak. Jika nilai t-hitung < nilai t-tabel maka H0 diterima. Hipotesis Penelitian Dampak Tata Rung Kota (X1):

H0: Dampak Tata Rung Kota (X1) tidak mempunyai pengaruh yang signifikan terhadap Pengurangan Kemacetan DKI Jakarta (Y)

Ha: Dampak Tata Rung Kota (X1) mempunyai pengaruh yang signifikan terhadap Pengurangan Kemacetan DKI Jakarta (Y)

Hasil uji menujukkan nilai t-hitung 8,490 > 2, 871 nilai t tabel, maka kesimpulannya $\mathrm{H} 0$ ditolak maka Dampak Tata Rung Kota (X1) mempunyai pengaruh yang signifikan terhadap Pengurangan Kemacetan DKI Jakarta (Y). Hipotesis Penelitian Antusias Masyarakat (X2):

Ha: Antusias Masyarakat (X2) mempunyai pengaruh yang signifikan terhadap Pengurangan Kemacetan DKI Jakarta (Y)

H0: Antusias Masyarakat (X2) tidak mempunyai pengaruh yang signifikan terhadap Pengurangan Kemacetan DKI Jakarta (Y)

Hasil uji menujukkan nilai t-hitung $-4,716<2$, 871 nilai t tabel, maka kesimpulannya $\mathrm{HO}$ diterima maka Antusias Masyarakat (X2) tidak mempunyai pengaruh yang signifikan terhadap Pengurangan Kemacetan DKI Jakarta (Y).
Tabel 8. Uji T

\begin{tabular}{|c|c|c|c|c|c|c|c|c|}
\hline & \multirow{2}{*}{ Model } & \multirow{2}{*}{\multicolumn{3}{|c|}{$\begin{array}{c}\begin{array}{c}\text { Standar } \\
\text { dized } \\
\text { Coeffici } \\
\text { ents }\end{array} \\
\text { Beta }\end{array}$}} & \multirow[t]{2}{*}{$\mathbf{t}$} & \multirow[t]{2}{*}{ Sig. } & \multicolumn{2}{|c|}{$\begin{array}{l}\text { Collinearity } \\
\text { Statistics }\end{array}$} \\
\hline & & & & & & & Tolerance & VIF \\
\hline \multirow[t]{3}{*}{1} & (Constant) & 8,361 & ,985 & & 8,490 & ,000 & & \\
\hline & $\begin{array}{l}\text { Dampak } \\
\text { Tata Rung } \\
\text { Kota (X1) }\end{array}$ &, 895 & 031 & ,910 & 29,264 & , 000 & ,745 & 1,342 \\
\hline & $\begin{array}{l}\text { Antusias } \\
\text { Masyarakat } \\
\text { (X2) }\end{array}$ &,- 139 & ,029 &,- 147 & $-4,716$ &, 000 & ,745 & 1,342 \\
\hline
\end{tabular}

\section{Uji Ketepatan Model (Uji F)}

Menurut (Fauzi, 2017) Dalam penelitian ini uji F digunakan untuk mengetahui tingkat signifikansi pengaruh variabel-variabel bebas (X1) secara bersama-sama (simultan) terhadap variabel terikat $(\mathrm{Y})$. Hipotesis yang diajukan dalam pengajuian ini adalah:

$\mathrm{H} 0$ : Variabel bebas (X) tidak mempunyai pengaruh yang signifikan secara bersama terhadap variabel terikat $(\mathrm{Y})$

Ha: Variabel bebas $(\mathrm{X})$ mempunyai pengaruh yang signifikan secara bersama-sama terhadap variabel terikat (Y).

Kriterian pengajuan hipotesisnya adalah sebagai berikut: Dengan cara membandingkan nilai F-hitung dengan nilai F-tabel. Jika nilai F-hitung >nilai F-tabel maka H0 ditolak. Jika nilai F-hitung < nilai F-tabel maka $\mathrm{H} 0$ diterima.

Hasil pengujian menujukkan nilai F-hitung 496,028 > 3.01 nilai F-tabel maka H0 ditolak, dengan demikian Dampak Tata Rung Kota (X1) dan Antusias Masyarakat (X2) secara bersama-sama mempunyai pengaruh yang signifikan terhadap Pengurangan Kemacetan DKI Jakarta (Y).

Tabel 10. Uji F

\begin{tabular}{lcrrrr}
\multicolumn{6}{c}{ ANOVA $^{\text {a }}$} \\
\hline Model & $\begin{array}{c}\text { Sum of } \\
\text { Squares }\end{array}$ & \multicolumn{1}{c}{ df } & $\begin{array}{c}\text { Mean } \\
\text { Square }\end{array}$ & F & Sig. \\
\hline 1 Regression & 4358,823 & 2 & 2179,411 & 496,028 &, $000^{\mathrm{b}}$ \\
Residual & 1735,521 & 395 & 4,394 & & \\
Total & 6094,344 & 397 & & & \\
\hline
\end{tabular}

a. Dependent Variable: Pengurangan Kemacetan DKI Jakarta (Y)

b. Predictors: (Constant), Antusias Masyarakat (X2), Dampak Tata Rung Kota (X1)

\section{SIMPULAN DAN SARAN}

Berdasarkan hasil dari penelitian menjukkan hasil Dampak Tata Rung Kota (X1) dan Antusias Masyarakat (X2) secara bersama-sama mempunyai pengaruh yang signifikan terhadap Pengurangan Kemacetan DKI Jakarta (Y), dengan jumlah F-hitung 496,028, lebih besar dari F-tabel 3.01. Dengan adanya MRT diharapkan dapat menguraikan kemacetan di 
DKI Jakarta. Semoga dengan berlakukanya peraturan genap ganjil dapat menarik minat pemilik kendaraan umum untuk beralih kendaraan untuk menggunakan transportasi umum salah satunya MRT Jakarta.

\section{DAFTAR PUSTAKA}

Fatuhudin, D. (2015). Metode Penelitian. Sidoarjo: Zifatama Publisher.

Fauzi, A. H. (2017). Pantai Syariah Pulau Santen. Banyuwangi: LPPM Institut Agama Islam Ibrahimy.

Muslim, A. (2018). Kerjasama Pemerintah Kota Makassar Dengan Singapura Dalam Pengembangan Smart City Dibidang Transportasi. eJournal Ilmu Hubungan Internasional. 15471560.

Oktavia, N. (2015). Sistematika Penulisan Karya Ilmiah. Yogyakarta: Deepublish.

Rustiadi, E. dll. (2017). Perencanaan dan Pengembangan Wilayah. Jakarta: Yayasan Pustaka Obor Indonesia.
Santoso, S. (2018). Menguasai Statistik dengan SPSS 25. Jakarta: PT. Elex Media Komputindo Jakarta.

Sihmanto. (2010). 2 Juta Keliling Filipina dalam 10 Hari. Yogyakarta: 8-First.

Sina, P. G. (n.d.). Mindset is Power. Bogor: Guepedia.

Sitinjak, E. (2004). Model Matriks Konsumen Untuk Menciptakan Suprior Customer Value. Jakarta: PT. Gramedia Pustaka Utama.

Sri \& Pamungkas, B. (2014). Ganti Rezim Ganti Sistim Pergulatan Muguasai Nusantara. SriBintang Pamungkas.

Susantono, B. (2014). Revolusi Transportasi. Jakarta: PT Gramedia Pustaka Utama.

Timotius, K. H. (2017). Metodologi Penelitian. Yogyakarta: ANDI.

Umar, H. (2003). Metode Riset Bisnis. Jakarta: PT. Gramedia Pustaka Utama.

Yunus, W. (2014). Pengantar Hukum Tata Ruang. Jakarta: Prenadamedia Group. 